\title{
Energy and hygrothermal performance of built- in mineral wool thermal insulations
}

\author{
Balázs Nagy ${ }^{1, *}$, and Tamás K. Simon ${ }^{1}$ \\ ${ }^{1}$ Budapest University of Technology and Economics, Faculty of Civil Engineering, Department of \\ Construction Materials and Technologies, Mủegyetem rkp. 3. K.I.85., 1111 Budapest, Hungary
}

\begin{abstract}
The paper analyses the monitoring measurement results on energy performance and hygrothermal behaviour of built-in rock and glass mineral wool thermal insulations in an energy efficiently refurbished typical single-family dwelling house in Hungary. The experimental monitoring measurements included an external weather station; internal air condition measurements; temperature, relative humidity and heat flux sensors in the layers of the facade and attic. An energy meter was installed into the heating systems. Apart from the insulated one, the energy consumption of an uninsulated but identical family house close by to the refurbished one was monitored as control. In the paper, apart from comparing the energy performance of the monitored buildings, the conjugated heat and moisture behaviour of the built-in mineral wool insulations were examined and compared to their design values and conditions. The temperature and moisture correction factors were evaluated. The paper presents laboratory measurements on the thermal conductivity of built-in and etalon mineral wool insulation samples also. The circumstances were set according to the experienced built-in conditions in the monitored buildings and compares the energy and hygrothermal performance of new and aged insulations.
\end{abstract}

\section{Introduction}

In 2013, a Hungarian mineral wool manufacturer and distributor company initiated a new experiment and publicity campaign [1]. The primary aim was to demonstrate the energy consumption reduction which resulted by intensive thermal insulation in a clear and easy to understand manner. For this purpose, two families and their two detached family homes were selected by a public competition. The two buildings were almost identical in size, layout and construction, and were located within a few kilometres from each other in the Northern Alföld (Lowland) region of Hungary. The first building, henceforth building 'A', in the town of Hajdúnánás was insulated at the company's expense, while building ' $\mathrm{B}$ ' in the nearby town of Hajdúdorog was left uninsulated as a control building (Fig. 1). A monitoring system was planned and set up to measure and record the relevant quantities. An additional research was proposed to comparatively measure the built-in hygrothermal

\footnotetext{
*Corresponding author: nagy.balazs@epito.bme.hu
} 
performance of the stone mineral wool external thermal insulation system (ETICS) on the facade wall and the glass mineral wool attic insulation, which were used in building ' $\mathrm{A}$ '.

\section{Methodology}

\subsection{Measurement of the boundary conditions}

A weather station mounted on the unused chimney of building 'A', at every 15 minutes measured the external boundary conditions like: dry-bulb temperature, relative humidity (RH), atmospheric pressure, wind speed and direction, as well as the precipitation above the roof. In both buildings, internal boundary conditions like: dry-bulb temperature and relative humidity were recorded in all of the rooms, and the families were instructed to follow similar heating and ventilation patterns for the duration of the project.

\subsection{Measurement of the attic and walls}

The attic and facade wall insulation variations and the process of sensor installations are presented in Fig. 1 and 2. The measurements lasted for a whole heating season, from the $27^{\text {th }}$ of September in 2013 until $31^{\text {st }}$ of March in 2014. At the facade wall a generally used construction method was applied (only patches of adhesive mortar was used instead of continuous mortar strips). This study shows the adverse effects of the lack of a proper adhesive mortar layer between the wall and the insulation, i.e. if a thin layer of air is formed behind the insulation. The measured facade wall was oriented to south-east direction, and measured across its cross-section with sensors in between each layer and one sensor in the middle of the $20 \mathrm{~cm}$ thick insulation as well. As in case of many other existing detached family houses, the insulation of the slab between the interior and the attic space was made without refurbishment of the roof and so the lack of addition of a reflecting foil underneath the roofing tiles, the humidity (as well as the wind) was able to penetrate into the attics. Therefore, vapour permeable underlay was laid on the top of the glass mineral wool insulating layer, to protect it. Sensors were installed into each accessible layer of the insulated attic slab and in the middle of the $25 \mathrm{~cm}$ thick insulation as well. The heat flow densities were measured with an Omega HFS-3 thin plate heat flux meter and a 16-bit ADC with an integrated surface temperature sensing K-type thermocouple at the interior surface of the wall. The temperature and relative humidity sensors were Sensirion SHT 75 type, having sensitivity in temperature measurement of $\pm 0.5 \mathrm{~K}$ and in humidity measurement of $\pm 2 \%$. The external surface temperature was measured with a digital temperature sensor, having a similar accuracy.
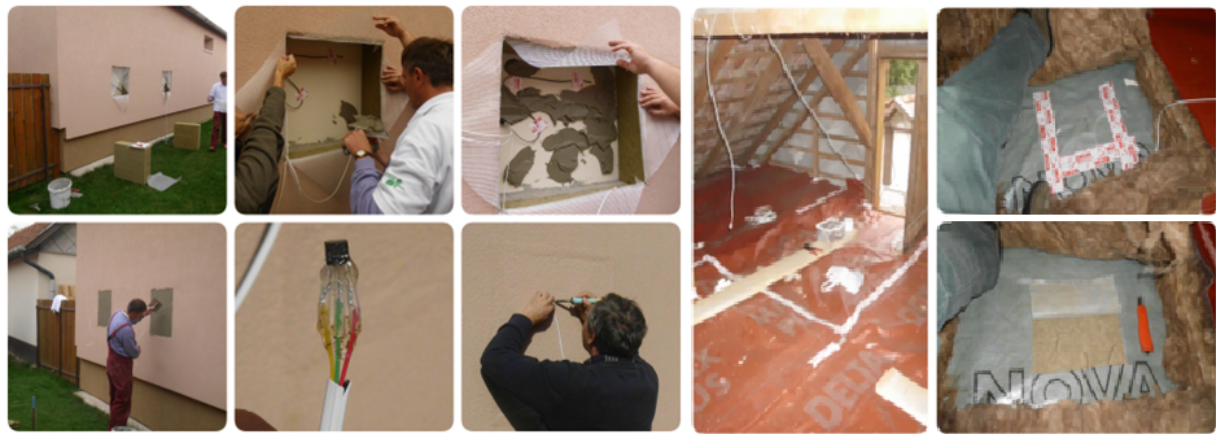

Fig. 1. Sensor fixing in ETICS insulation layer (left) and in attic insulation layer (right) in building 'A'. 

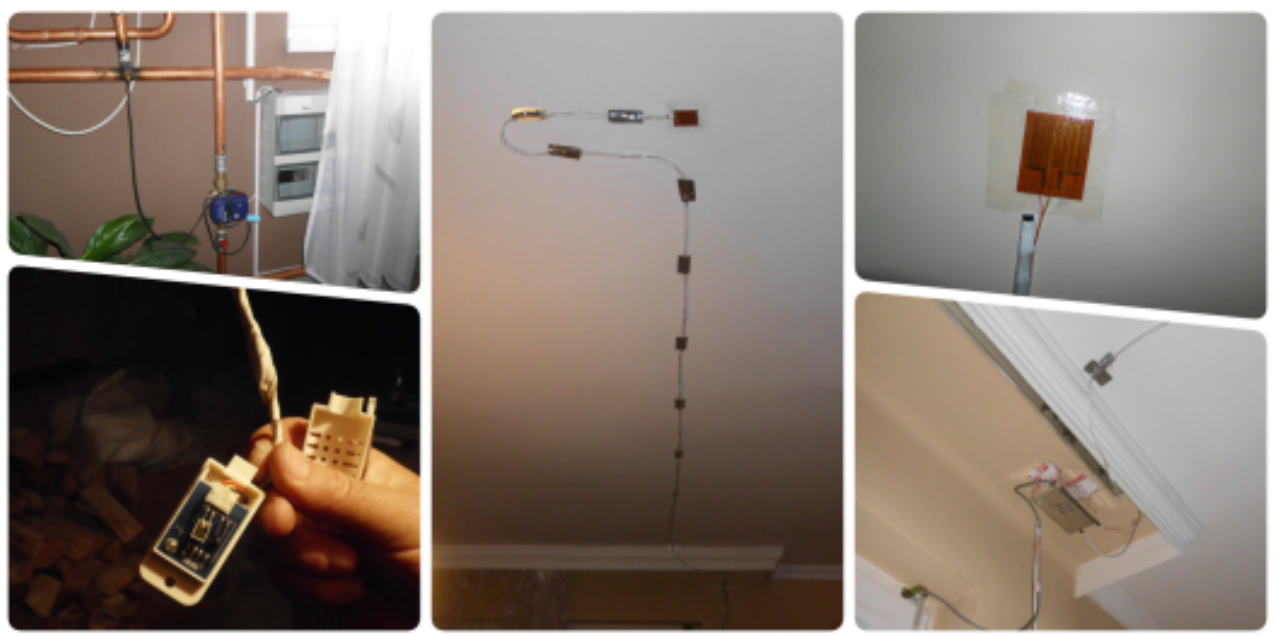

Fig. 2. Energy meter, temperature and RH sensor placement inside building 'A'.

\subsection{Measurement of the energy used for heating}

The energy used for heating was also logged in every 15 minutes with a thermal energy meter (Fig. 2.), which was installed into the heating system (both houses had a gas boiler and radiators using water as the heating medium), while gas consumption was calculated by using the nominal values of the boilers efficiency to provide an easier comparison. The energy monitoring took place for the same time period as the monitoring of the materials in 2.2 above. A summary of the results can be found on a Hungarian webpage [1].

\subsection{Temperature and relative humidity data evaluation}

To illustrate our measured dataset from the $12^{\text {th }}$ of October till $20^{\text {th }}$ of May, we used data contouring. We represented the values in a $3 \mathrm{D}$ map to show the temperature and relative humidity distributions of the building structures. To determine the values between the measured points Kriging interpolation method was applied. Kriging is a geostatistical interpolation technique that considers both the distance and the degree of variation between known data points when estimating values in unknown areas. It can be seen as a point interpolation which requires a point map as an input, results in a raster map with estimations as the output, and optionally an error map may be obtaind.

\subsection{Calculation of the momentary thermal conductivities}

The constantly changing value of thermal conductivity can be determined from temperature and relative humidity data, which was recorded during the measurements. The value of the thermal conductivity of each layer can be determined according to ISO 10456:2007 [2] based on the temperature and relative humidity values which are measured in the layers and at the layer boundaries:

$$
\lambda_{2}=\lambda_{1} \cdot F_{T} \cdot F_{m} \cdot F_{a}=\lambda_{1} \cdot e^{f_{T}\left(T_{2}-T_{1}\right)} \cdot e^{f_{u}\left(U_{2}-U_{1}\right)} \cdot 1
$$

where $\lambda_{2}$ is the adjusted (design) thermal conductivity; $\lambda_{1}$ is the declared (catalogue) value of thermal conductivity; $\mathrm{F}_{\mathrm{T}}, \mathrm{F}_{\mathrm{m}}$ and $\mathrm{F}_{\mathrm{a}}$ are the temperature, moisture and age conversion factors of which the last one was set to 1 , since no further ageing was considered. $\mathrm{f}_{\mathrm{T}}$ is 
temperature conversion coefficient; $\left(\mathrm{T}_{2}-\mathrm{T}_{1}\right)$ represent the temperature difference between the real life application and laboratory mean temperature of the material. The factor $f_{u}$ is moisture conversion coefficient; $\left(\mathrm{U}_{2}-\mathrm{U}_{1}\right)$ is the moisture content difference between the real life application and laboratory measurement of declared values. For moisture conversion, the connection between the measured $\mathrm{RH}$ in a material and the moisture content is the moisture storage function.

\subsection{Calculation of the thermal transmittances}

Under steady-state conditions the thermal transmittance (U-value) can be obtained by measuring the heat flow density through an element, and recording the temperature on both sides of the element. Since steady-state conditions are never achieved in practice, there are many different methods to eliminate a difficult calculation. In this case we assumed that, the mean values of heat flow densities and temperatures over a long-time period give a good estimate for the steady-state condition. There are several stages of U-value measuring process, including the selection and calibration of heat flow meters and temperature sensors, then the measurements and analysis of the data. For calculating the U-value from measured temperature data and heat flow densities, averaging method according to ISO 9869-1:2014 was used [3]. There are three conditions, and the test can be completed when these conditions are fulfilled.

The first condition is that the duration of the test must exceed 72 hours, while the temperature is stable around the heat flow meter. The second is that the R-value obtained at the end of the test cannot deviate more than $\pm 5 \%$ from the value obtained 24 hours before. The last condition is that the R-value obtained by analysing the data from the first-time period during $\operatorname{INT}(2 \cdot \mathrm{DT} / 3)$ days does not deviate more than $\pm 5 \%$ from the values obtained from the data of the last time period of the same duration, where DT is the duration of the test in days and INT is representing the integer part. This method assumes that the U-value can be obtained by dividing the mean heat flow density by the mean temperature difference. In such a way an estimated U-value is obtained by the following formula:

$$
\mathrm{U}=\frac{\sum \mathrm{q}}{\sum\left(\mathrm{T}_{\mathrm{i}}-\mathrm{T}_{\mathrm{e}}\right)}
$$

where $q$ is the heat flux, $T_{i}$ is the internal temperature and $T_{e}$ is the external temperature.

The U-value can be determined by using the following formulas from the surface temperatures, or from the thermal resistance values:

$$
U=\frac{q}{T_{i}-T_{e}}=h_{s i} \cdot \frac{T_{i}-T_{s}}{T_{i}-T_{e}}=\left(h_{c i}+\varepsilon \cdot \sigma \cdot \frac{T_{i}^{4}-T_{s}^{4}}{T_{i}-T_{s}}\right) \cdot \frac{T_{i}-T_{s}}{T_{i}-T_{e}}=\frac{1}{\frac{1}{h_{c i}+h_{r i}}+\sum \frac{d_{j}}{\lambda_{2, j}}+\frac{1}{h_{c e}+h_{r e}}}
$$

where $h_{c i}$ is the internal convective part and $h_{r i}$ is the internal radiative part of the $h_{s i}$ internal surface heat transfer coefficient, $\varepsilon$ is the emissivity factor of the surface, $\sigma$ is the Stefan-Boltzmann constant, $T_{i}$ and $T_{e}$ stands for internal and external air temperatures, $T_{s}$ is the temperature of the measured internal surface. Here $\lambda_{2}$ is the temperature and moisture content adjusted thermal conductivity of a $d_{j}$ thick material layer. While $h_{c e}$ is the external convective part and $h_{r e}$ is the external radiative part of $h_{\text {se }}$ external surface heat transfer coefficient according to ISO 6946:2017 [4].

\subsection{Laboratory measurement of the thermal conductivity of insulations}

Under steady-state conditions the thermal conductivity can be obtained by laboratory measurements by using a guarded hot plate apparatus according to EN 12667:2001 [5] as 
can be seen on Fig. 3. The measurements were carried out on 3-3 pre-conditioned etalons and already built-in mineral wool samples respectively by using the following, measured parameters:

$$
\lambda=\frac{\mathrm{V} \cdot \mathrm{I} \cdot \mathrm{d}}{\mathrm{A} \cdot \Delta \mathrm{T}}
$$

where $\mathrm{V}$ is the voltage of the heating plate, $\mathrm{I}$ is the current of the heating plate, $\mathrm{d}$ is the sample thickness, $\mathrm{A}$ is the measured area and $\Delta \mathrm{T}$ is the temperature difference between the cooled and the heated surfaces. The samples were packed into thin PE foil to maintain their relative humidity during the measurements, and also framed by aluminium tape and glass mineral wool insulation to avoid temperature change and moisture migration from the sides. The declared thermal conductivity of the samples were also calculated by using a confident statistical tolerance interval of $90 \%$ according to ISO 10456:2007 [2].
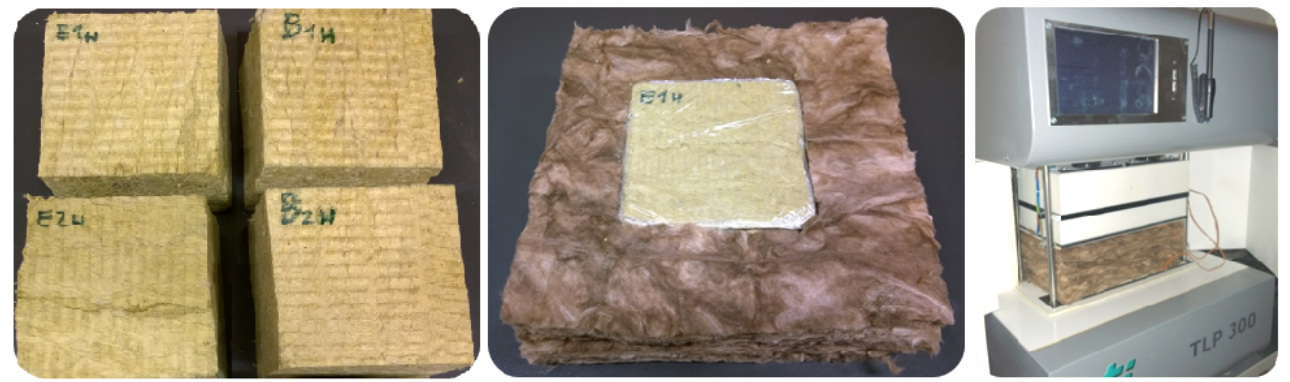

Fig. 3. Etalon and built-in samples measured in guarded hot plate apparatus.

\section{Results}

\subsection{Energy used for heating}

The heating energy was logged betwen 27th September 2013 - 31th March 2014 with a thermal energy meter built into the heating system (Fig. 4.). The energy consumption reached its peak in both cases at the end of January. During this period the maximum energy consumption was $0.58 \mathrm{GJ}$ in the ' $\mathrm{B}$ ' uninsulated house during a day, and at the same time it was less than a half of that, $0.26 \mathrm{GJ}$ in the ' $\mathrm{A}$ ' insulated house. If the overall energy consumption is summed up, the insulated house in Hajdúnánás used 23.73 GJ while the uninsulated house in Hajdúdorog used $52.6 \mathrm{GJ}$; therefore we can see that the insulated house used almost $55 \%$ less energy than the uninsulated one during the investigated period.

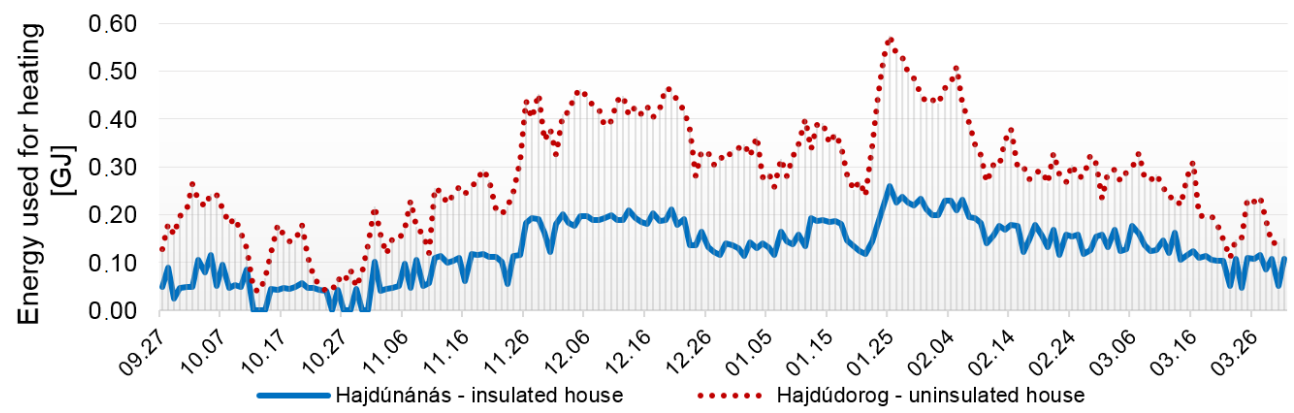

Fig. 4. Energy used for heating in a single heating season. 


\subsection{Hygrothermal behaviour of the insulated facade wall}

Fig. 5. show the measured and Kriging interpolated temperature and relative humidity distributions in the cross sections over time. The average temperature in the ETICS was $12,51{ }^{\circ} \mathrm{C}$, while minimum temperatures in ETICS was $2.51{ }^{\circ} \mathrm{C}$ and the maximum temperatures was $27.45{ }^{\circ} \mathrm{C}$. The average $\mathrm{RH}$ was $61.34 \%$ which equals to $2.95 \mathrm{~kg} / \mathrm{m}^{3}$ moisture content calculated using laboratory measured sorption isotherm of the material, while the minimum was $31.8 \%\left(1,27 \mathrm{~kg} / \mathrm{m}^{3}\right.$ moisture $)$, and the maximum was $77.25 \%(4,27$ $\mathrm{kg} / \mathrm{m}^{3}$ moisture).

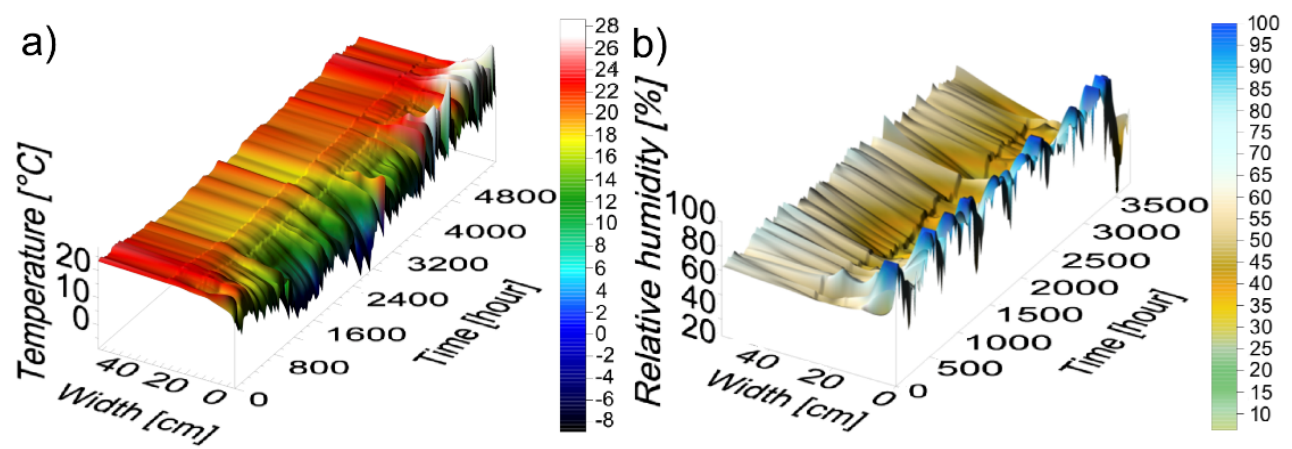

Fig. 5 a) Temperature distribution and b) RH distribution in the insulated wall.

Based on the measured values, the obtained average thermal conversion factor was 1.016 , and the average moisture conversion factor was 1.011. It is observable that both temperature conversion and moisture conversion factors are in the range of $1-2 \%$ of increment, together resulting a 2,7\% increase in the ETICS thermal conductivity. Therefore the average thermal conductivity of the ETICS during the whole measurement must be corrected by the conversion factors, the design value was $0.0399 \mathrm{~W} / \mathrm{mK}$ (in which the thermal conductivity of the rock mineral wool was $0.035 \mathrm{~W} / \mathrm{mK}$, determined at $10^{\circ} \mathrm{C}$ and using dry samples, but ETICS contains the mortar and thin plaster layer as well). In life the on-site performance of the ETICS gave $0.041 \mathrm{~W} / \mathrm{mK}$ as a result for the U-value.

\subsection{Hygrothermal behaviour of the insulated attic slab}

The attics form a transition between the interior and outdoor spaces, the roof protects the thermal insulation on the ceiling from the impacts of the weather, but this protection is not $100 \%$ efficient, especially when reflecting roof foil is not used. The temperature and relative humidity across the sections are presented in Fig 6. The average temperature of the $25 \mathrm{~cm}$ thick glass mineral wool insulating layer was $14.97{ }^{\circ} \mathrm{C}$, the minimum was $4.55^{\circ} \mathrm{C}$ and the maximum was $29.54{ }^{\circ} \mathrm{C}$. The average relative humidity in the insulating layer was $59.24 \%$ which correspond to $4.64 \mathrm{~kg} / \mathrm{m}^{3}$ moisture content calculated according to it's sorption isotherm, the minimum was $31.95 \%\left(2.82 \mathrm{~kg} / \mathrm{m}^{3}\right.$ moisture $)$ and the maximum was $94.16 \%\left(10.84 \mathrm{~kg} / \mathrm{m}^{3}\right.$ moisture). It is observable that the mineral wool made out of glass had more moisture in absolute value compared to rock mineral wool, due to the material's different sorption isotherms.

Based on the measured temperature and $\mathrm{RH}$ data, the average temperature correction factor was 1.018 and the average moisture correction factor was 1.121 showing that in attics, where no roof foil is used under the tiles, the moisture accumulation could significantly change the thermal conductivity of the insulation. The adjusted thermal 
conductivity of the insulation was $0.044 \mathrm{~W} / \mathrm{mK}$, which was $14 \%$ higher, than the 0.039 $\mathrm{W} / \mathrm{mK}$ declared glass mineral wool thermal conductivity, what is used for design.

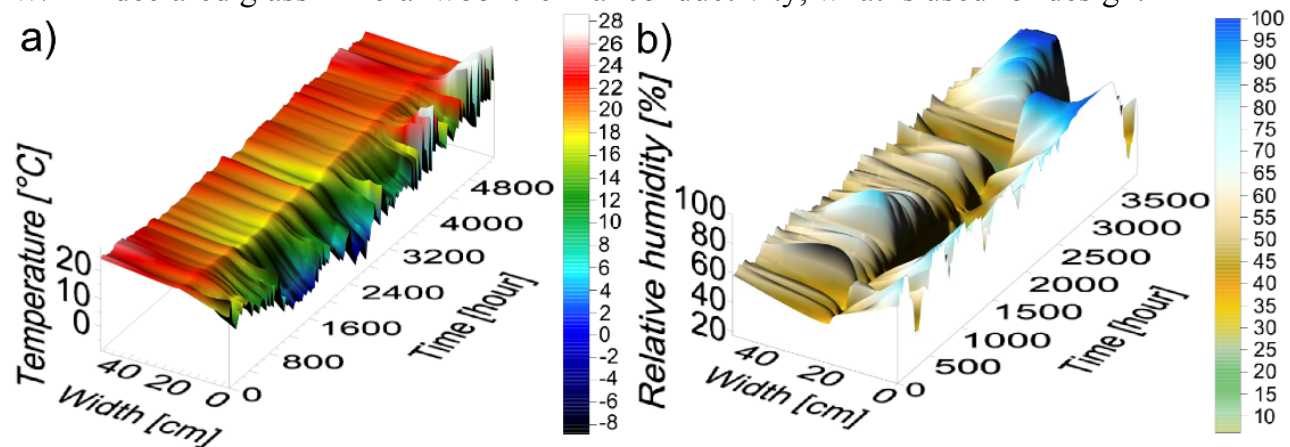

Fig. 6. a) Temperature distribution and b) RH distribution in the insulated attic.

\subsection{Thermal transmittances of facade and attic}

Based on the in-situ measured values, by using Eq. 2, the U-values of the wall sections and the ceiling were calculated. These U-values take the dynamic boundary conditions, layer temperatures and RH changes into account. The average U-value of the insulated facade wall was $0.16 \mathrm{~W} \cdot \mathrm{m}^{-2} \cdot \mathrm{K}^{-1}$, while the steady calculated $\mathrm{U}$-value was $0.15 \mathrm{~W} \cdot \mathrm{m}^{-2} \cdot \mathrm{K}^{-1}$. The average U-value of the insulated attic section was $0.191 \mathrm{~W} \cdot \mathrm{m}^{-2} \cdot \mathrm{K}^{-1}$, while the calculated one was $0.17 \mathrm{~W} \cdot \mathrm{m}^{-2} \cdot \mathrm{K}^{-1}$.

By using the measured data, $h_{s}$ surface heat transfer coefficients as well as $R_{s}$ surface resistances can be obtained. The average internal horizontal surface heat transfer coefficient for the wall was $\mathrm{h}_{\mathrm{si}}=8.49 \mathrm{~W} \cdot \mathrm{m}^{-2} \cdot \mathrm{K}^{-1}\left(\mathrm{R}_{\mathrm{si}}=0.118 \mathrm{~m}^{2} \cdot \mathrm{K} \cdot \mathrm{W}^{-1}\right)$ and the external surface heat transfer coefficient was $\mathrm{h}_{\mathrm{se}}=26.82 \mathrm{~W} \cdot \mathrm{m}^{-2} \cdot \mathrm{K}^{-1}\left(\mathrm{R}_{\mathrm{se}}=0.037 \mathrm{~m}^{2} \cdot \mathrm{K} \cdot \mathrm{W}^{-1}\right)$ which values are close to the values given in the standard [4], however the distribution changed during the time of the measurement.

\subsection{Laboratory measured thermal conductivity of new and built-in insulations}

The average temperature of the rock mineral wool was $12.29{ }^{\circ} \mathrm{C}$ and the average $\mathrm{RH}$ was $59.06 \%$ during the on-site measurements, according to the examined monitoring results. We used new "etalon" and already built-in and cut-out $15 \times 15 \times 10 \mathrm{~cm}$ rock mineral wool thermal insulation samples to recreate the average thermal conductivity, occurred during the on-site measurements. We tried to pre-condition the samples before the guarded hot plate measurements as close as possible to the average on-site measured values. The samples were stored at a constant temperature chamber at $12{ }^{\circ} \mathrm{C}$, where magnesium nitrate salt solution was used to create $57 \%$ relative humidity. After the samples reached mass equilibrium state, the thermal conductivity measurements were started.

We used a firm compression on the samples to ensure the continuous connection and minimal resistance between the temperature measuring plates and the samples, therefore samples were compressed around $94-95 \mathrm{~mm}$ in their thickness with the same $400 \mathrm{~N}$ compressing force, what showed that in this case built-in samples maintained their mechanical properties when compared to etalon samples. Simon [6] investigated that moisture damages or improper curing of the mineral wool could lead to compressive strength loss resulting the compression of the mineral wool layer in roof construction. In that case, however the thermal conductivity of built-in mineral wool only slightly increased, but decreasing in thickness could further decrease the insulating layer's thermal resistance. 
The measured thermal conductivities are given in Table 1. The difference between etalon and built-in samples and the declared thermal conductivity was $2.86 \%$.

Table 1. Declared thermal conductivity of etalon and built-in mineral wool insulation

\begin{tabular}{|c|c|c|c|c|c|}
\hline $\begin{array}{l}\text { Sign of } \\
\text { sample }\end{array}$ & $\begin{array}{c}\text { Size of } \\
\text { samples }[\mathrm{mm}]\end{array}$ & $\begin{array}{c}\text { Compressed } \\
\text { thickness } \\
{[\mathrm{mm}]} \\
\end{array}$ & \begin{tabular}{|c|}
$\begin{array}{c}\text { Compressed } \\
\text { density } \\
{\left[\mathrm{kg} / \mathrm{m}^{3}\right]}\end{array}$ \\
\end{tabular} & $\begin{array}{c}\text { Thermal } \\
\text { conductivity at } \\
12^{\circ} \mathrm{C}[\mathrm{W} / \mathrm{mK}]\end{array}$ & $\begin{array}{c}\text { Thermal } \\
\text { conductivity } \\
\lambda_{90 / 90}[\mathrm{~W} / \mathrm{mK}]\end{array}$ \\
\hline E1 & $149.81 \times 151.40$ & 94.11 & 139.509 & 0.0349 & \multirow{3}{*}{0.035} \\
\hline E2 & $149.99 \times 151.58$ & 94.74 & 133.153 & 0.0348 & \\
\hline E3 & $150.12 \times 150.72$ & 94.87 & 127.735 & 0.0346 & \\
\hline B1 & $148.38 \times 149.49$ & 94.89 & 129.467 & 0.0360 & \multirow{3}{*}{0.036} \\
\hline B2 & $154.31 \times 149.69$ & 94.70 & 131.116 & 0.0361 & \\
\hline B3 & $149.14 \times 149.29$ & 94.54 & 130.265 & 0.0359 & \\
\hline
\end{tabular}

\section{Summary}

In the study we analysed by measured datasets the energy performance of an house which is thermally insulated and which is not and the hygrothermal behaviour of the insulated building construction of a family house during an entire heating season. The measurements proved that thermally insulating a family house, significantly increase its energy efficiency and could end up saving more than 50\% energy consumption. We examined the temperature and RH distributions, thermal conductivities and thermal transmittances of the facade wall and attic slab. The results showed that the rock mineral wool ETICS on the facade wall had $2.7 \%$ higher average thermal conductivity than the designed value. The attic's glass mineral wool insulation had $14 \%$ higher thermal conductivity due to increased moisture content in the insulation. However, laboratory measured built-in rock mineral wool samples had $2.86 \%$ higher declared values at the same conditions as new and etalon samples, which could mean that the differences between thermal conductivities of rock mineral wool may have occurred due to the aging of the built-in insulation material.

\section{콩}

Supported by the ÚNKP-17-3 New National Excellence Program of the Ministry of Human Capacities. The authors are gratefully acknowledges Ms. Dóra Szagri, Dr. Dániel Bakonyi and Dr. Rita Nemes for their help and contribution to the research.

\section{References}

1. http://www.nalamszigetelnek.hu (January, 2018)

2. ISO 10456 (2007)

3. ISO 9869-1 (2014)

4. ISO 6946 (2017)

5. EN 12667 (2001)

6. T.K. Simon, L. Mlinárik, V. Vargha, J. Build. Physics 39, 285-294 (2015) 